\title{
Reliability of Water Transmission Systems
}

\author{
Alaa Hisham Naguib, Mohamed Hassan Abdel Razik, Mohamed Ali Fergala, Sherien Ali Elagroudy \\ Public Works Department, Faculty of Engineering, \\ Ain Shams University, \\ Cairo, Egypt
}

\begin{abstract}
Reliability of water transmission system is generally ignored in design. A simplified methodology is developed for the assessment of water transmission systems reliability. Design guidelines are introduced to improve system reliability. The simulation approach is used to calculate the water systems reliability. Results indicated that in order to achieve a system target reliability of $99 \%$, transmission pipelines with break rate exceeding $0.05 \mathrm{break} / \mathrm{km} /$ year and 1-day repair time should be duplicated if longer than $73 \mathrm{~km}$. Pumps with break rate exceeding 3 break/year and 5-day repair time should have standby capacity of at least $150 \%, 67 \%$ or $25 \%$ in case of 2,3 or 4 working pumps respectively. If the target reliability cannot be achieved, then water storage at destination should be provided. A design formula is proposed to calculate the required minimum storage.
\end{abstract}

Keywords- Water Network, Reliability, Availability, Mechanical Reliability, Hydraulic Reliability, Break Rate.

\section{INTRODUCTION}

There are many definitions for water networks reliability in the literature:

- Kaufmann et al. [1] defined reliability as the probability that the system performs its specified tasks under specified conditions during a specified time.

- Cullinane et al. [2] defined reliability as the ability of the system to provide service with an acceptable level of interruption in spite of abnormal conditions.

- Goulter et al. [3] defined reliability as the ability of the system to meet the demands that are placed on it where demands are specified in terms of amount of flows to be supplied and the range of pressures at which those flow rates must be provided.

- Al-Zahrani et al. [4] defined reliability as the ability of the network to deliver water to consumers in the required quantity and quality at suitable pressure head.

In the current study, water supply system reliability is defined as ability of the system to supply the required demand with sufficient pressure under normal and abnormal conditions. Normal conditions mean common operation with no failure of any component of the network, while abnormal conditions mean the network operation with one or more components out of service. Reliability is measured by a value from zero to $100 \%$ representing the ratio of hydraulic performance between abnormal and normal conditions. System reliability of $100 \%$ means the system is fully functional under break of any system component.

The following definitions are adopted in the study:

- Hydraulic reliability, which describes the performance of the system to satisfy the required water demand.
- Component reliability is defined as the probability that a component has no failure during its life time.

- Mechanical reliability, which measures the effect of component failure on the system performance, mechanical reliability depends on both hydraulic reliability and component reliability.

- Network/System reliability, is the minimum mechanical reliability of all system components.

For example, a single supply pipeline would have zero hydraulic reliability but $97 \%$ mechanical reliability if its probability of failure is $3 \%$. If there are many cases of failure, then the network reliability is defined as the minimum mechanical reliability.

\section{RELIABILITY ANALYSIS APPROACHES}

Over the last few decades, several methods have been developed for the assessment of water systems reliability. However, there is no widely accepted approach or methodology introduced for water network reliability analysis. Ostfeld [5] classified the approaches to assessment of water systems reliability into three groups: analytical (connectivity), simulation (hydraulic) and heuristic (entropy) approaches.

\section{A. Analytical Approach}

Analytical approaches deal with the layout of water distribution network, which is associated with the probability that a given network keeps physically connected, given its component reliabilities. These are the approaches linked to the above-mentioned concepts of connectivity and reachability that are not based on hydraulic simulations. One of the methods used to evaluate network reliability is the Minimum Cut Set Method, where cut set are defined as a set of failed elements whose failure cause the isolation of node/s from the system, without taking into consideration the effect of these failed elements on the network or the condition of other elements.

\section{B. Simulation Approach}

Simulation approaches deal with the hydraulic reliability and availability. Thus, they analyses the hydraulic performance of the network, i.e. a suppling of the required quantities and qualities of water at adequate pressure to the appropriate locations at any given time. Therefore, these approaches rely heavily on hydraulic models and require very good information about the network layout and operation, including the records related to the component failures.

Goulter et al. [6] introduced a reliability method based on relationship between flow and pressure. If demand is met but at reduced flow, then the network reliability decreases. Also, if the pressure satisfies the minimum required threshold value but the demand is not satisfied then the network reliability 
decreases. In case of both pressure and demand are not met the network reliability is greatly reduced.

\section{Heuristic Approach}

Heuristic approaches do not measure the performance of the water system directly they assess other attributes such as energy or power used which are expected to have strong correlation with reliability, as another method for measuring network reliability. Many approaches have been developed such as Entropy-Based Method by K. Awamah et al. [7], Network Resilience by Prasad et al. [8], Performance Index by Dziedzic et al. [9].

\section{MODELLING OF COMPONENT FAILURE}

Component reliability, is defined as the probability that a component has no failure during an interval from time 0 to time $T$ [10]. It best describes non-repairable components, where after failure they have to be replaced. But, in water networks most components are repairable, so component failure is best described as component availability.

Availability (A) is the percentage of time where a component is functionally operating, while the component is considered Unavailable $(U)$ when it is in failure or repair status [11].

Pipe failure models are statistical models which use historical data of pipe failures to detect their failure patterns, then use these patterns to predict in probability of pipe failure future. Statistical models can be classified into two main categories according to Kleiner et al. [12], Liu et al. [13] and Scheidegger et al. [14]:

\section{A. Deterministic models}

These models are developed from historical data of component failure in order to predict future failure rate (e.g. number of failures per year or failure rate or time to next failure).

Shamir et al. [15] used regression analysis to acquire a break prediction model that relates a pipes breakage to the exponent of its age. This model is used to forecast break rates to group of homogenous pipes based on historical data.

Walski et al. [16] update the exponential model by adding two factors to the model, the first factor is for the historical previous breaks in the pipes based on that broken pipes are more likely to be broken again, the second factor is the effect of different diameter sizes in the break pattern.

Clark et al. [17] developed two regression models. The first model to predict the life time between installation and the first break, and the second model is to predict the number of breaks after the first break, It was concluded that a pipe with early failure will suffer more break event more than that pipe that has a late failure.

Achim et al. [18] developed a new application of neural networks ANN model for pipeline failure prediction. Results show higher correlations with recorded data than other existing statistical models. The used database was large but was incomplete and not dependable. Factors affecting pipeline breakage were missing from the database.
Parvizsedghy et al. [19] developed a model for assessment of water pipelines deterioration. Deterioration factors were divided into three main groups: physical, environmental, and operational. The model showed that pipe age is the dominant parameter for predicting the failure rates.

\section{B. Probabilistic models}

Models that explicitly and quantitively consider most of the covariates in the analysis which make these models more general for estimating future breakage rates of water pipes.

Cox [20] introduced a general form of the prediction hazards model which is used to estimate the time to next failure.

Goulter et al. [21] and $\mathrm{Su}$ et al. [22] used Poisson probability distribution to determine the probability of failure of individual pipes.

Andreou et al. [23] developed a vector covariant hazard function during the analysis of their failure data, they observed that the time intervals between first three consecutive failures had an ascending order. After the third failure, these intervals seemed to be constant. So, the developed model was characterized by two stages, the first stage where fewer breaks take place and represented by the proportional hazard function, and the second stage more frequent breaks which was represented by a Poisson distribution model.

Eisenbeis et al. [24] applied the accelerated lifetime model for a number of failure histories in Norway and France. The approach was to lengthen the pipe break history through creating a sample of pipe breaks by randomly selecting break dates that follow the shape of the survival function of the general model. The author reported good predictions using this method.

Kleiner et al. [25] developed computer application I-WARP (Individual Water mAin Renewal Planner), which is a tool to analyses the failure records of break patterns of individual water pipelines. I-WARP is based on the assumption that breaks on an individual pipe occur as a non-homogeneous Poisson process.

Scheidegger et al. [26] developed a model based on the assumptions that the time to the first failure is modeled by Weibull distribution and all the successive failures are modeled as exponential distribution. These assumptions result in an inflexible failure rate that cannot represent deterioration over time and is only partly manipulated by the previous failures.

\section{MEthodology}

This study is concerned with the development of new simplified approach to be incorporated in design to assess network reliability. Guidelines for improving the reliability of water supply systems are introduced which would assist designers and decision makers in water system planning.

The target for the required mechanical reliability should be set for the design, on which the combination between the availability and the hydraulic reliability can be determined to meet the required mechanical reliability. The methodology is divided into seven steps as discussed below and described in the flow chart presented in Figure 1.

Step 1: Define system data and cases of failure. 
Step 2: Calculate Hydraulic Reliability.

Step 3: Calculate Component Availability.

Step 4: Calculate Mechanical Reliability.

Step 5: Calculate Network Reliability.

Step 6: Improve Network Reliability.

Step 7: Add water storage (if necessary).

\section{A. Step 1: System Definition}

The first step is to identify the water system components. A typical water transmission system usually consists of pumps, and transmission pipeline. Water storage tanks may be added at destination to cover demand fluctuation and emergencies. The Base Scenario assumes no storage tank at destination and all system components are fully functional. Then cases representing the failure of each component are identified which are: failure of the transmission pipeline or failure of a working pump.

\section{B. Step 2: Hydraulic Reliability}

In water transmission systems, hydraulic reliability is estimated as the percentage of flow delivered from source to destination under abnormal conditions in relation to the delivered flow under normal conditions. Eq. 1 represents the hydraulic reliability of the system in case of one element is in failure conditions.

$$
R_{M}=\frac{n-1}{n}
$$

Where;

$R_{H}=$ Hydraulic Reliability.

$\mathrm{n}=$ number of working elements (pipes or pumps).

For example, if two pipelines are working and one of them is out of service $50 \%$ of the flow will be delivered which represents the hydraulic reliability. Also if there are three working pumps and one of them is out of service then $66.6 \%$ of the flow will be delivered which represents the hydraulic reliability in this case. The above calculated hydraulic reliability is approximate, and actual calculation through hydraulic analysis would result in slightly higher values.

\section{Step 3: Component Availability}

In the current study deterministic models are used to describe component availability for pipes and pumps, as described below:

\section{1) Pipes Availability}

The probability of pipe failure is derived from the failure rate (expressed as number of breaks per unit length of pipe per unit time). Pipe availability depends on historical break data, time to repair and pipeline length as presented in Eq. 2 and 3 and illustrated in Figure 2.

$$
A=1-R_{f}
$$

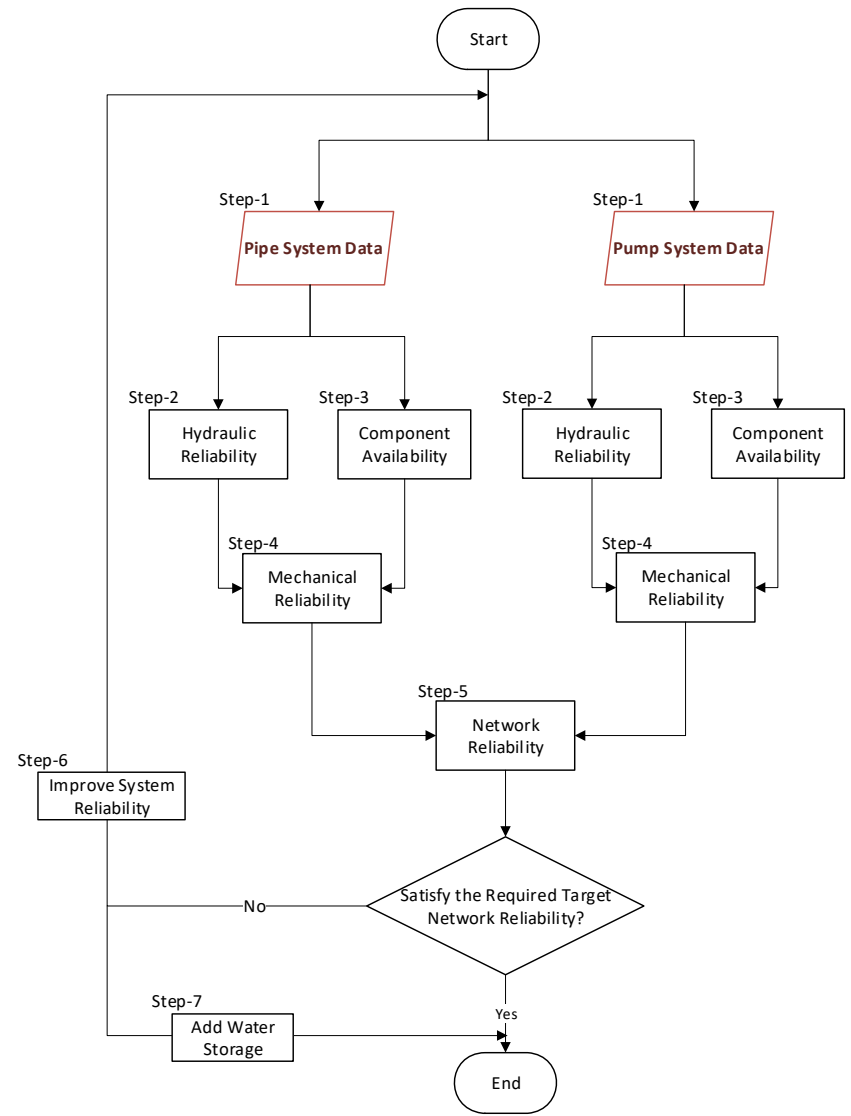

Figure 1 Adopted Methodology for Network Reliability Analysis

Where;

$A=$ Component Availability.

$P_{f}=$ Probability of failure.

$\lambda=$ Break Rate (break. $\mathrm{km}^{-1}$. year-1) which depends on historical data

$\mathrm{L}=$ Pipe length $(\mathrm{km})$.

$T R=$ Time of Repair in days.

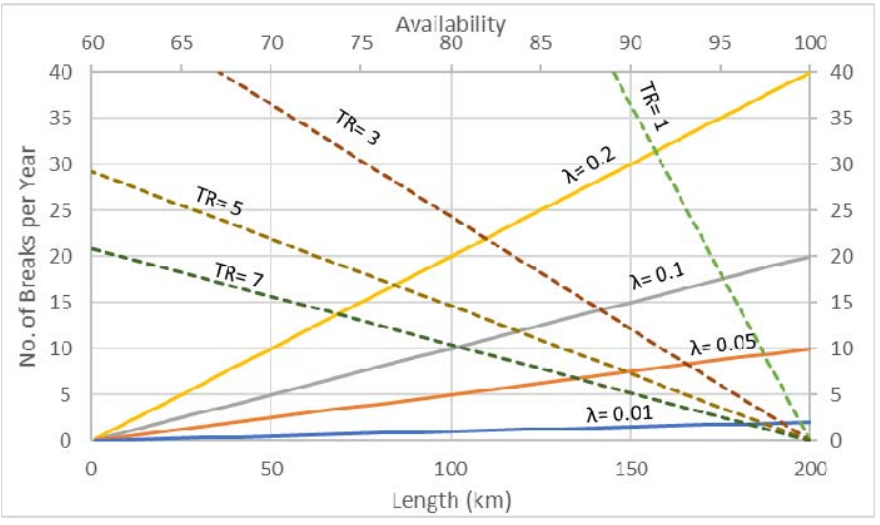

Figure 2 Pipes Availability 


\section{2) Pumps Availability}

Pumps availability depends on number of working pumps, pump break rate, time to repair and percentage of standby pumps as presented in Eq. 4 and Eq. 5, as illustrated in Figure 3.

$$
P_{f}(P \text { wmp })=\frac{\pi N G T R}{2 G \pi}
$$

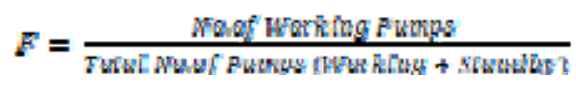

Where;

\section{$\lambda=$ Pump Break Rate (break. year ${ }^{-1}$ )}

$F=$ Pump Break Rate Correction Factor, taking into consideration the percentage of standby pumps. As the percentage of standby pumps increases, the operation time decreases, and pump break rate decreases by the factor $F$. For example, in case of 2 working +1 standby pump, the operation time of each pump is reduced from 12 to 8 months per year; and consequently, pump break rate decreases by $67 \%$.

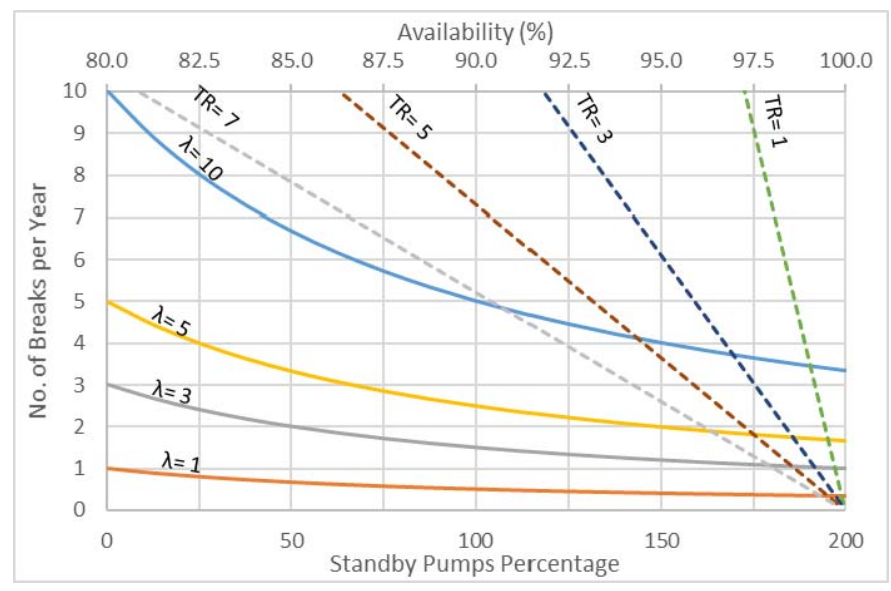

Figure 3 Pumps Availability

\section{Step 4: Mechanical Reliability}

Mechanical Reliability depends on both hydraulic reliability and component availability. For example, if the hydraulic reliability is dropped to $40 \%$ for $20 \%$ of the year, mechanical reliability is estimated by the area under the curve in Figure 4 which is $88 \%$, as expressed by Eq. 6 .

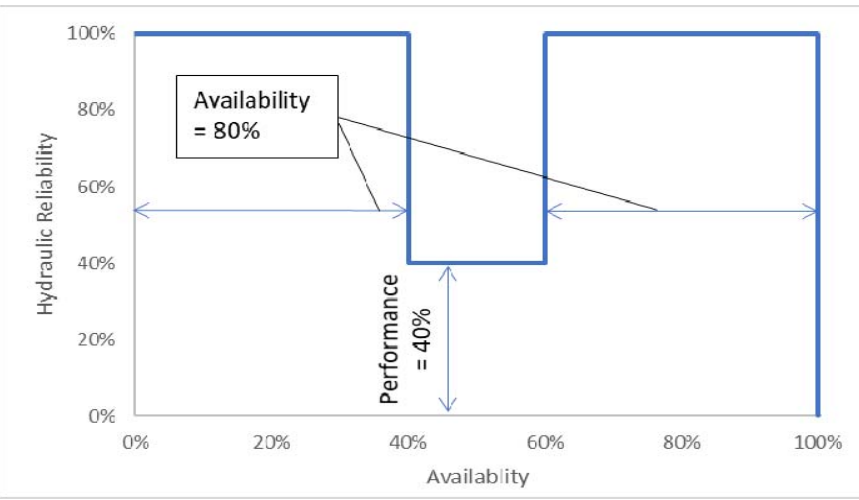

Figure 4 Calculation of Mechanical Reliability

$$
R_{M}=1-\left[\left(1-R_{H}[*(1-A)]\right.\right.
$$

Where;

$$
\begin{aligned}
& R_{M}=\text { Mechanical Reliability } \\
& R_{H}=\text { Hydraulic Reliability } \\
& A=\text { Component Availability }
\end{aligned}
$$

Pipes mechanical reliability depends on its length, break rate, number of parallel lines and time of repair. Pumps mechanical reliability depends on its number of working pumps, percentage if standby pumps, break rate and time of repair. The mechanical reliability of the water supply system can be determined, as shown in Figure 5.

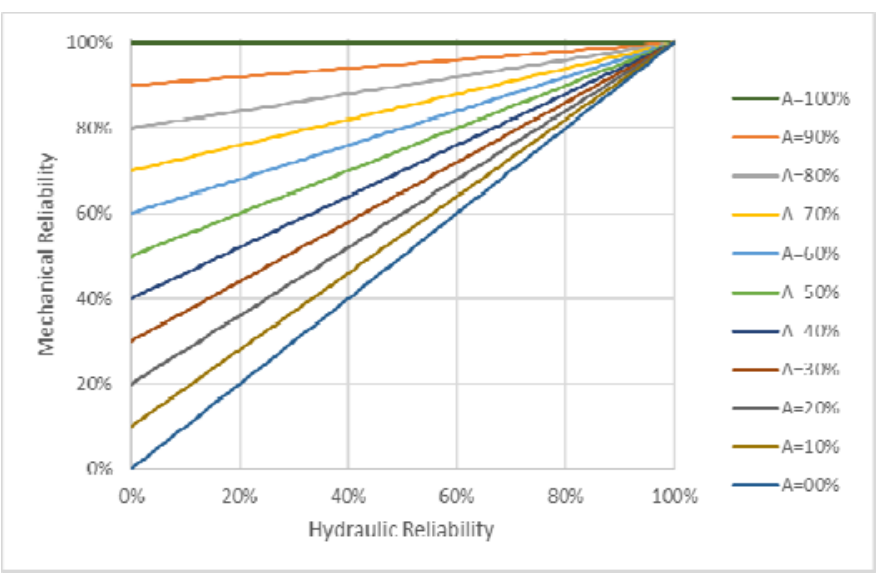

Figure 4 Mechanical Reliability of Water Supply System

\section{E. Step 5: Network Reliability}

The Network Reliability is defined as the minimum mechanical reliability in the studied failure cases for the system.

\section{F. Step 6: Improve System Reliability}

The mechanical reliability can be improved by upgrading one of the system components as illustrated below:

- Improving pipe reliability by:

0 adding pipes in parallel.

o using pipes of higher-grade materials.

o preventive maintenance of the system components.

- Improving pump reliability by:

o increasing number of working pumps.

0 increasing the percentage of standby pumps.

o preventive maintenance of the system components.

- Adding water storage to cover the system deficiency during emergency periods.

\section{G. Step 7: Add Water Storage}

If the target minimum reliability cannot be achieved through system upgrade, water storage at destination is 
required to increase the mechanical reliability of the system. The required minimum storage can be estimated by Eq. 7 to Eq. 9.

$\Delta \mathbb{R}_{\mathrm{S}}=\mathrm{R}_{\mathrm{SIt}}-\mathbb{R}_{\mathrm{Slo}}=\left[1-\left(1-R_{H}^{2}\right) *\left(1-A_{\mathrm{f}}\right)\right]-\left[1-\left(1-R_{H}\right) *\left(1-A_{\alpha}\right)\right]$

Which can be simplified into Eq. 8 as follows.

$\Delta A=A_{\tau}-A_{0}=\frac{\Delta \mathbb{R}_{\mathrm{DI}}}{1-R_{H}}$

Then the minimum storage is calculated by Eq. 9 .

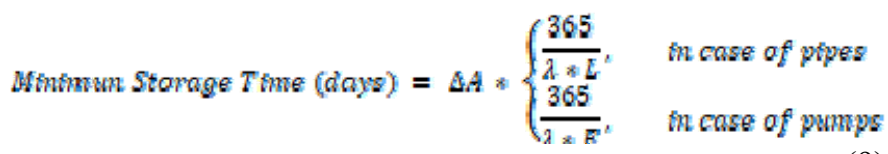

Where;

$\Delta \mathbb{R}_{\mathrm{MI}}=$ required increase in mechanical reliability

$\mathbb{R}_{\mathbb{M}}=$ target mechanical reliability

$\mathbb{R}_{\text {Mos }}=$ water network mechanical reliability

$R_{K}=$ hydraulic reliability

$A_{z}=$ target availability

$A_{0}=$ achieved availability

$\Delta A=$ Required Increase in System Availability

The required increase in system availability can be achieved by storage to cover the system deficiency during failure cases, so the required storage is determined based on the estimated mean time to repair and the required increase in the in the system availability.

\section{DESIGN GUIDELINES}

In order to incorporate the reliability analysis in design process, the following approach is developed.

\section{A. Pipes Reliability}

To achieve the target mechanical reliability, pipes lengths, break rate and number of parallel pipes are to be set as identified in Table 1 and Figure 6.

Table 1 MaXimum PiPe Lengths to AChiEve Target Mechanical RELIABILITY

\begin{tabular}{|l|l|l|l|l|l|}
\hline $\begin{array}{c}\text { Target } \\
\text { Mechanical } \\
\text { Reliability }\end{array}$ & $\begin{array}{c}\text { Pipe Break } \\
\text { Rate } \\
\text { (break/km/ } \\
\text { year) }\end{array}$ & \multicolumn{4}{|c|}{ Max. Length (km) } \\
\cline { 3 - 6 } & & $\begin{array}{c}|c| \\
\text { 1 Pipes }\end{array}$ & \multicolumn{2}{|c|}{ 2 Pipes } \\
\cline { 3 - 6 } & & $\begin{array}{c}\text { Repair } \\
\text { Time }\end{array}$ & $\begin{array}{c}\text { 2 Days } \\
\text { Repair } \\
\text { Time }\end{array}$ & $\begin{array}{c}\text { 1 Day } \\
\text { Repair } \\
\text { Time }\end{array}$ & $\begin{array}{c}\text { 2 Days } \\
\text { Repair } \\
\text { Time }\end{array}$ \\
\hline $99 \%$ & 0.05 & 73.0 & 36.5 & 146.0 & 73.0 \\
\cline { 2 - 6 } & 0.10 & 36.5 & 18.3 & 73.0 & 36.5 \\
\cline { 2 - 6 } & 0.20 & 18.3 & 9.1 & 36.5 & 18.3 \\
\hline
\end{tabular}

\begin{tabular}{|l|l|l|l|l|l|}
\hline \multirow{3}{*}{$\begin{array}{c}\text { Target } \\
\text { Mechanical } \\
\text { Reliability }\end{array}$} & \multirow{2}{*}{$\begin{array}{c}\text { Pipe Break } \\
\text { Rate } \\
\text { (break/km/ } \\
\text { year) }\end{array}$} & \multicolumn{4}{|c|}{ Max. Length (km) } \\
\cline { 3 - 6 } & & $\begin{array}{c}|c| \\
\text { 1 Day } \\
\text { Repair } \\
\text { Time }\end{array}$ & $\begin{array}{c}\text { 2 Days } \\
\text { Repair } \\
\text { Time }\end{array}$ & $\begin{array}{c}\text { 1 Day } \\
\text { Repair } \\
\text { Time }\end{array}$ & $\begin{array}{c}\text { 2 Days } \\
\text { Repair } \\
\text { Time }\end{array}$ \\
\hline $98 \%$ & 0.05 & 146.0 & 73.0 & 292.0 & 146.0 \\
\cline { 3 - 6 } & 0.10 & 73.0 & 36.5 & 146.0 & 73.0 \\
\cline { 2 - 6 } & 0.20 & 36.5 & 18.3 & 73.0 & 36.5 \\
\hline $97 \%$ & 0.05 & 219.0 & 109.5 & 438.0 & 219.0 \\
\cline { 2 - 6 } & 0.10 & 109.5 & 54.8 & 219.0 & 109.5 \\
\cline { 2 - 6 } & 0.20 & 54.8 & 27.4 & 109.5 & 54.8 \\
\hline
\end{tabular}

Figure 7 shows a graphical flow chart that can be used to estimate the mechanical reliability of pipe in case of one single transmission pipeline.

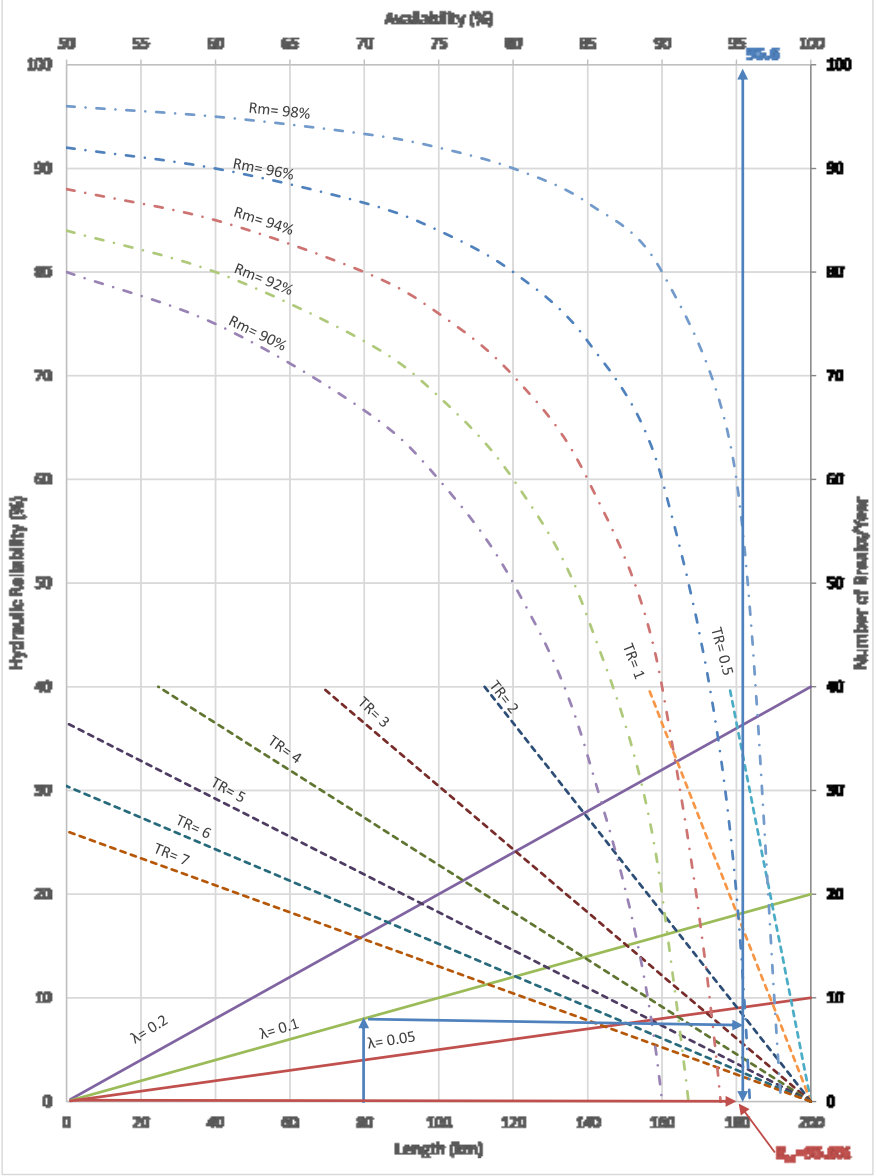

Figure 5 Mechanical Reliability of Pipes

It can be concluded that in order to achieve system reliability exceeding $99 \%$ at break rate of $0.05 \mathrm{break} / \mathrm{km} / \mathrm{year}$, single pipe can be used for lengths up to $73 \mathrm{~km}$ considering a 1-day repair time, and double pipe for lengths up to $146 \mathrm{~km}$.

\section{B. Pumps Reliability}

To achieve a minimum target mechanical reliability, number of working and standby pumps and pump break rates should comply with the values presented in Table 2 and Figure 7. 
Table 2 Minimum Number of Standby Pumps to Achieve Target Mechanical Reliability

\begin{tabular}{|c|c|c|c|c|c|c|c|c|c|}
\hline \multirow{3}{*}{$\begin{array}{c}\text { Target } \\
\text { Mechanical } \\
\text { Reliability }\end{array}$} & \multirow{3}{*}{$\begin{array}{c}\text { Pumps } \\
\text { Break Rate } \\
\text { (break/year) }\end{array}$} & \multicolumn{8}{|c|}{ Minimum Number Standby Pumps } \\
\hline & & \multicolumn{4}{|c|}{5 Days Repair Time } & \multicolumn{4}{|c|}{7 Days Repair Time } \\
\hline & & $\begin{array}{c}1 \\
\text { Working } \\
\text { Pump }\end{array}$ & $\begin{array}{c}2 \\
\text { Working } \\
\text { Pumps }\end{array}$ & $\begin{array}{c}3 \\
\text { Working } \\
\text { Pumps }\end{array}$ & $\begin{array}{c}4 \\
\text { Working } \\
\text { Pumps }\end{array}$ & $\begin{array}{c}1 \\
\text { Working } \\
\text { Pump }\end{array}$ & $\begin{array}{c}2 \\
\text { Working } \\
\text { Pumps }\end{array}$ & $\begin{array}{c}3 \\
\text { Working } \\
\text { Pumps }\end{array}$ & $\begin{array}{c}4 \\
\text { Working } \\
\text { Pumps }\end{array}$ \\
\hline \multirow[t]{3}{*}{$99 \%$} & 1 & 1 & 0 & 0 & 0 & 1 & 0 & 0 & 0 \\
\hline & 3 & & 3 & 2 & 1 & & 4 & 3 & 2 \\
\hline & 5 & & & 4 & 3 & & & & 6 \\
\hline \multirow[t]{3}{*}{$98 \%$} & 1 & 0 & 0 & 0 & 0 & 0 & 0 & 0 & 0 \\
\hline & 3 & 2 & 1 & 1 & 0 & 2 & 1 & 1 & 0 \\
\hline & 5 & & 2 & 1 & 0 & & 3 & 2 & 1 \\
\hline \multirow[t]{3}{*}{$97 \%$} & 1 & 0 & 0 & 0 & 0 & 0 & 0 & 0 & 0 \\
\hline & 3 & 1 & 0 & 0 & 0 & 1 & 0 & 0 & 0 \\
\hline & 5 & 2 & 1 & 0 & 0 & & 2 & 1 & 0 \\
\hline
\end{tabular}

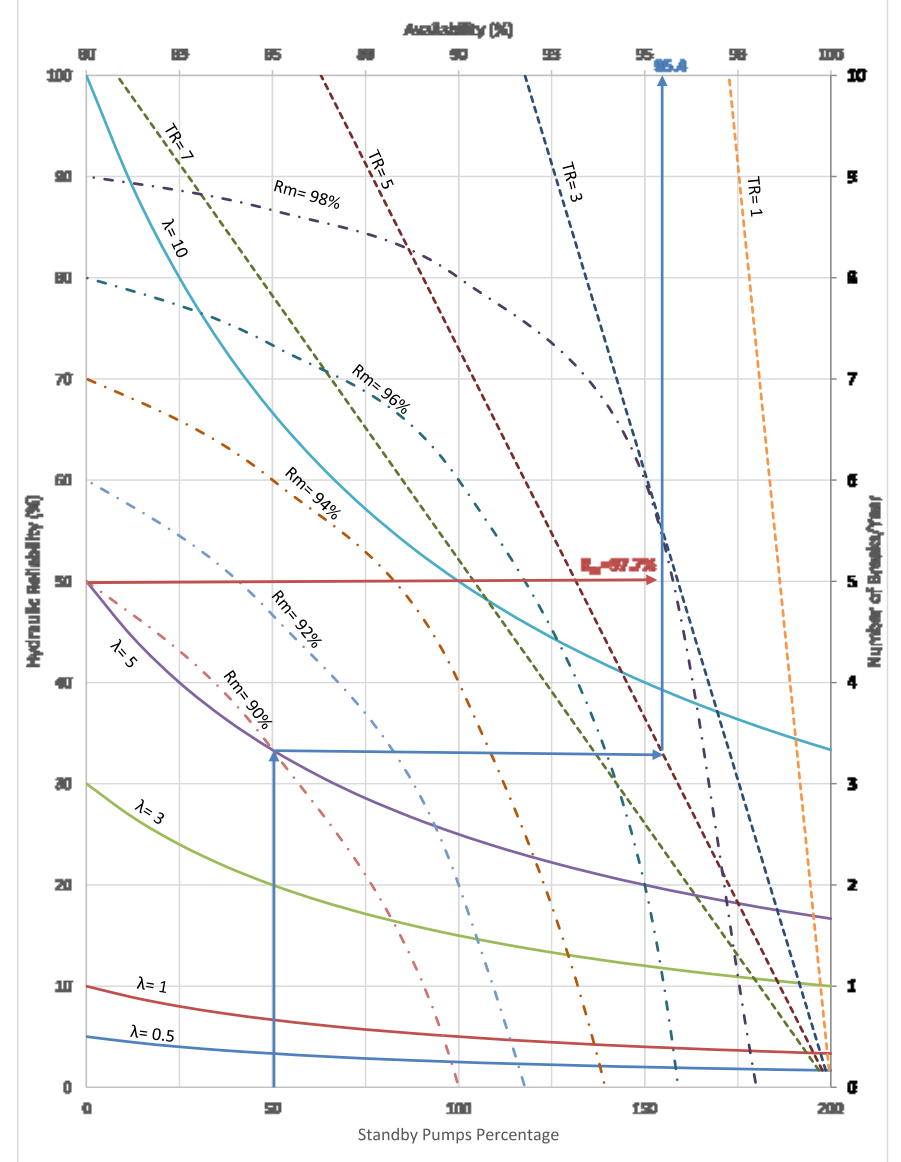

Figure 7 Mechanical Reliability of Pumps

It is concluded from Table 2 and Figure 7 that, to achieve system reliability of at least $99 \%$ for 3 working pumps with at least 2 standby pumps are required with break rate less than 3 break/year considering 5 days for repair time, if the break rate exceeds 3 break/year then it is required to increase number of working pumps or the standby pumps. The maximum reliability that can be achieved by 1 working pump is $99 \%$ if the standby pump is at least $100 \%$ and the break rate is less than 1 break/year considering 5 days for repair time. So, increasing the number of working elements reduces the effect of component failure on the system reliability.

\section{Water Storage}

The required increase in network reliability can be achieved by storage to cover the system deficiency during failure cases, so the required storage is determined based on the required increase in the in the network reliability, hydraulic reliability and the number of breaks per year which can be obtained from Figure 6 and Figure 7. Figure 8 shows the required storage time to satisfy the required increase in network availability.

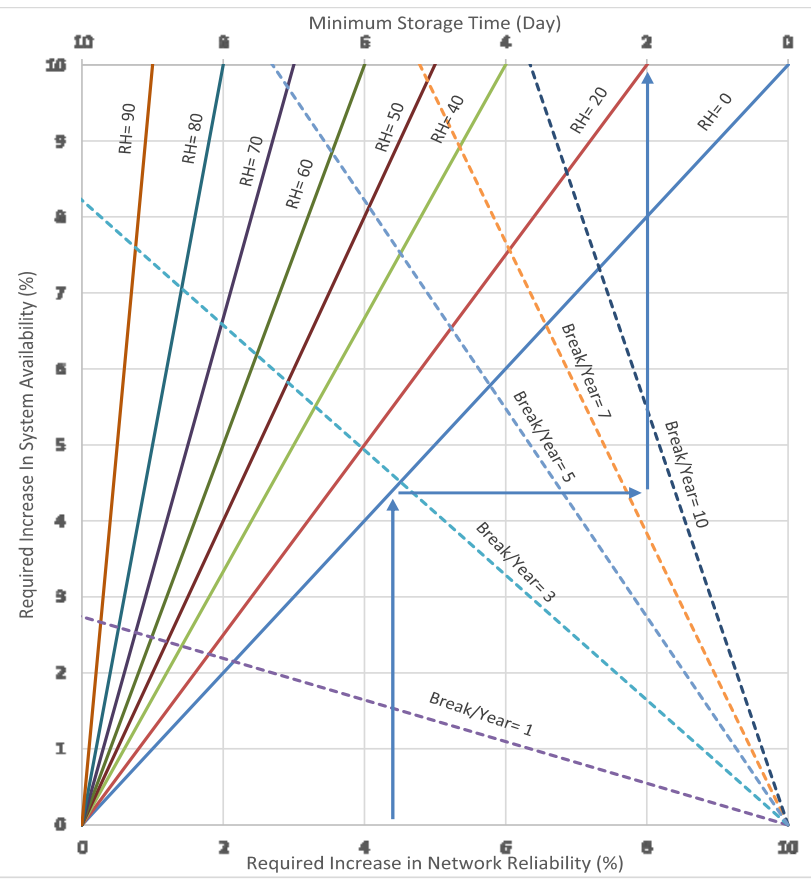

Figure 8 Required Minimum Storage Time 


\section{APPLICATION}

\section{A. Step 1 - System Definition}

A sample water supply system is prepared for illustration purpose as shown in Figure 9. The system consists of:

- $\quad 2$ working pumps and 1 standby pump with break rate of 5 break/year and repair time of 5 days.

- a single transmission pipe of length $80 \mathrm{~km}$ with the break rate is $0.1 \mathrm{break} / \mathrm{km} / \mathrm{year}$ and the repair time is 2 days.

- No water storage at destination.

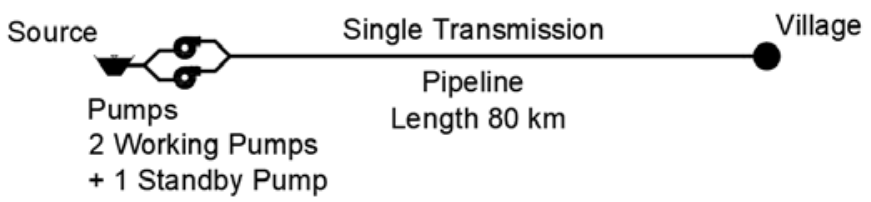

Figure 6 Sample Water Supply System

\section{B. Step 2 - Hydraulic Reliability}

The hydraulic reliability for each failure case is calculated by substituting in Eq. 1 .

- For pipe failure case, the hydraulic reliability is $0 \%$.

- $\quad$ For pump failure case, the hydraulic reliability is $50 \%$.

\section{Step 3 - Component Availability}

- The pipe availability is $95.6 \%$, calculated by substituting in Eq. $2 \& 3$ or from Figure 6.

- The pump availability is $95.4 \%$, calculated by substituting in Eq. 4 \& 5 or from Figure 7.

\section{Step 4-Mechanical Reliability}

The mechanical reliability for each failure case is calculated by substituting in Eq. 6 .

- For pipe failure case, the mechanical reliability is $95.6 \%$ or using Figure 6.

- For pump failure case, the mechanical reliability is $97.7 \%$ or using Figure 7.

\section{E. Step 5 - Network Reliability}

Then the network reliability of the water supply system is the minimum of both failure cases which is the pipe failure case with mechanical reliability $95.6 \%$.

\section{F. Step 6-System Improvement}

To upgrade the water supply system to improve the network reliability, the following means can be adopted:

- Add a parallel pipe, then the mechanical reliability will be $97.8 \%$.

- Using pipes of more resistant material and schedule preventive maintenance to reduce the pipe break rate and repair time, assumed to be $0.05 \mathrm{break} / \mathrm{km} / \mathrm{year}$ and 1-day repair time, then the mechanical reliability will be $98.9 \%$.

- Increasing the number of working pumps to be 3 working pumps, then the mechanical reliability will be $98.3 \%$.

- Increase the number of standby pumps to be 2 standby pumps, then the mechanical reliability will be $98.3 \%$.

- Using pumps of higher quality and schedule preventive maintenance to reduce the pump break rate and repair time, assumed to be 3 break/year and 2-day repair time, then the mechanical reliability will be $99.5 \%$.

\section{G. Step 7 - Add Water Storage}

The network reliability can be improved by adding water storage at destination. The minimum required storage time can be determined from Figure 8 or by substituting in Eq. 8 \& 9, as follows:

- To achieve network reliability of $98 \%$, then the required minimum storage is 1.1 day.

- To achieve network reliability of $99 \%$, then the required minimum storage is 1.6 day.

- To achieve network reliability of $100 \%$, then the required minimum storage is 2 days, which is the minimum repair time of the system.

\section{CONCLUSIONS AND RECOMMENDATIONS}

Reliability of water transmission system is in general overlooked in design. A simplified 7-step approach is developed for the assessment of water transmission systems reliability, as follows:

Step 1: Define system data and cases of failure. The system data are:

- For pipes: number of pipes in parallel, length, break rate and repair time.

- For Pumps: number of working pumps, number of standby pumps, break rate and repair time.

Step 2: Calculate Hydraulic Reliability.

Step 3: Calculate Component Availability.

Step 4: Calculate Mechanical Reliability.

Step 5: Calculate Network Reliability.

Step 6: Improve Network Reliability, by:

- $\quad$ adding pipes in parallel.

- increasing number of working pumps or standby pumps.

- $\quad$ reducing the break rate by preventive maintenance of the system components or using high quality of pipe materials and pumps.

Step 7: Add water storage (if necessary).

- If target reliability cannot be achieved then water storage can be added at destination to cover the system 
deficiency during emergency periods, a design formula is proposed to calculate the required minimum storage.

Design guidelines to improve system reliability are introduced. In order to achieve a target minimum system reliability, the following design elements can be calculated:

- The maximum length of transmission pipelines.

- The minimum number of standby pumps.

- The minimum required storage at destination.

The proposed methodology is illustrated by a sample case study as follows:

- $\quad$ To achieve system reliability exceeding $99 \%$ at break rate of $0.05 \mathrm{break} / \mathrm{km} / \mathrm{year}$, and 1-day repair time, a single pipe can be used for lengths up to $73 \mathrm{~km}$.

- To achieve system reliability of at least $99 \%$ pumps with break rate exceeding 3 break/year and 5-day repair time should have standby capacity of at least $150 \%, 67 \%$ or $25 \%$ in case of 2,3 or 4 working pumps respectively.

\section{REFERENCES}

[1] A. Kaufmann, D. Grouchko and R. Croun, "Mathematical models for the study of the reliability of systems," Academic,, New York, US, 1977.

[2] M. Cullinane, K. Lansey and L. Mays, "Optimization availability-based design of water distribution networks," Journal of Hydraulic Engineering, vol. 118, no. 3, pp. 420-441, 1992.

[3] I. Goulter, "Analytical and simulation models for reliability analysis in water distribution systems," In: Cabrera E, Vela A (eds) Improving efficiency and reliability in water distribution systems. Kluwer Academic Publishers, 1995.

[4] M. A. Al-Zahrani and J. L. Syed, "Evaluation of municipal water distribution system reliability using minimum cut-set method," Journal of King Saud University - Engineering Sciences, vol. 18, no. 1, pp. 67-81, 2005.

[5] A. Ostfeld, "Reliability analysis of water distribution systems," Journal of Hydroinformatics, vol. 6, no. 4, pp. 281-294, 2004.

[6] Goulter, "Analytical and simulation models for reliability analysis in water distribution systems," Kluwer Academic Publishers, Valencia, Spain, 1995.

[7] K. Awumah, I. Goulter and S. K. Bhatt, "Entropy-based redundancy measures in water-distribution networks," Journal of Hydraulic Engineering, vol. 117, no. 5, pp. 595-614, 1991.

[8] Prasad, T. Devi and Park, Nam-Sik, "Multiobjective Genetic Algorithms for Design of Water Distribution Networks," Journal of Water Resources Planning and Management, vol. 130, no. 1, pp. 73-82, 2004.

[9] Dziedzic, Rebecca and Karney, Bryan W., "Performance Index for Water Distribution Networks under Multiple Loading Conditions," Journal of Water Resources Planning and Management, vol. 142, no. 1, 2016.

[10] N. Trifunovic, "Pattern Recognition For Reliability Assessment Of Water Distribution Networks," Ph.D. dissertation, UNESCO-IHE Institute for
Water Education, Delft Univ. of Technology, ISBN 978-0-415-62116-8, Delft, the Netherlands, 2012.

[11] L. Mays and Y.-K. Tung, "Hydrosystems Engineering and Management," McGraw-Hill Book. Co. ISBN 0-07-041146-8, New York, US, 1992.

[12] Y. Kleiner and B. Rajani, "Comprehensive review of structural deterioration of water mains : statistical models," Urban Water, vol. 3, pp. 131-150, 2001.

[13] Z. Liu, Y. Kleiner, B. Rajani, L. Wang and W. Condit, "Condition Assessment Technologies for Water Transmission and Distribution Systems," Environmental Protection Agency, U.S., 2012.

[14] A. Scheidegger, J. P. Leitao and L. Scholten, "Statistical failure models for water distribution pipes - a review from a unified perspective," Water Research, vol. 83, pp. 237-247, 2015.

[15] U. Shamir and C. Howard, "An Analytic Approach to Scheduling Pipe Replacement," Jornal of AWWA, no. 71, pp. 248-258, 1979.

[16] T. M. Walski and A. Pelliccia, "Economic Analysis of Water Main," Journal of AWWA, vol. 74, no. 3, pp. 140-147, 1982.

[17] R. M. Clark, C. L. Stafford and J. A. Goodrich, "Water Distribution Systems: A Spatial and Cost Evaluation," Journal of Water Resources Planning and Management, vol. 108, no. WR3, pp. 243-256, October 1982.

[18] D. Achim, F. Ghotb and K. J. McManus, "Prediction of Water Pipe Asset Life Using Neural Networks," ASCE Journal of Infrastructure Systems, vol. 13, no. 1, pp. 26-30, 2007.

[19] L. Parvizsedghy, I. Gkounti, A. S. T. Zayed, M. Alsharqawi, H. E. Chanati, M. El-Abbasy and F. Mosleh, "Deterioration Assessment Models for Water Pipelines," International Journal of Civil and Environmental Engineering, vol. 11, no. 7, 2017.

[20] D. R. Cox, "Regression Models and Life Tables," Journal of Royal Statistic Society, vol. 34, no. B, pp. 187-220, 1972.

[21] I. C. Goulter and A. V. Coals, "Quantitative Approaches to Reliability Assessment in Pipe Networks," Journal of Transportation Engineering, vol. 112 , no. 3 , pp. 287-301, 1986.

[22] Y. C. Su, L. W. Mays, N. Duan and K. E. Lansey, "Reliability based optimization model for water distribution systems," Journal of Hydraulic Engineering., vol. 114, no. 12, pp. 1539-1556, 1987.

[23] S. A. Andreou, D. H. Marks and R. M. Clark, "A new methodology for modelling break failure patterns in deteriorating water distribution systems: Theory," Advance in Water Resources, vol. 10, no. 1, pp. 2-10, 1987.

[24] P. Eisenbeis, J. Rostum and Y. Le Gat, "Statical Models for assessing the technical state of water networks - Some European experience," in AWWA Annual Conference, Chicago, 1999.

[25] Y. Kleiner and B. Rajani, "I-WARP: Individual water mAin renewal planner," Drinking Water Engineering and Science, vol. 3, no. 1, pp. 71$77,2010$.

[26] A. Scheidegger, L. Scholten, M. Maurer and P. Reichert, "Extension of pipe failure models to consider the absence of data from replaced pipes," Water Research, vol. 47, no. 11, pp. 3696-3705, 2013. 